Izvirni znanstveni članek/Article (1.01)

Bogoslovni vestnik/Theological Quarterly 81 (2021) 1, 9-21

Besedilo prejeto/Received:03/2021; sprejeto/Accepted:03/2021

UDK/UDC: 159.964

DOI: 10.34291/BV2021/01/Cvetek

(C) 2021 Cvetek, CC BY 4.0

Robert Cvetek

\title{
Videti sence, strmeti v Sonce: travma, potravmats- ka rast, bivanjska vprašanja in varanje samega sebe
}

Seeing Shadows, Staring at the Sun: Trauma, Post-traumatic Growth, Existential Questions and Self-Deception

Povžetek: Številne raziskave kažejo, da procesi v možganih, tako v fizičnem, še bolj pa v socialnem okolju, v veliki meri izbirajo, kaj bomo kot posamezniki opazili in naredili za pomembno, s tem pa si ustvarjamo tudi subjektivne sisteme za interpretacijo sveta in življenja. Travmatične izkušnje imajo zaradi specifične spominske narave pri tem posebno vlogo, zaradi pogoste navzočnosti ogroženosti življenja pa predvsem tudi za bivanjski vprašanji končnosti in smisla življenja. Ti dve vprašanji današnji družbi delata velike probleme, na nekatere njune vidike pa dajeta vera in religija prepotrebne in pomembne odgovore. Odgovore je treba sprejeti ne le na kognitivni in razumski ravni, ampak jih uvrstiti tudi v vedénje in življenje, predvsem pri žrtvah travme pa jih dajati v sočutnem, pristnem, ljubečem in varnem odnosu, v katerem je možno regulirati intenzivne afekte in anksioznost. Pri tem je lahko v veliko pomoč akademsko delo v smislu interdisciplinarnega dialoga, h kateremu močno poziva tudi papež Frančišek.

Ključne besede: travma, potravmatska rast, eksistencialna vprašanja, nenamerna slepota

Abstract: Numerous studies show that processes in our brain essentially select what we perceive and consider essential, both in the physical and even more so in the social environment. Thus, we also create subjective systems for interpreting the world and life. Because of the specific nature of memory, traumatic experiences play a unique role in this process, because of the frequent presence of life threats on such occasions, especially for the existential questions of the finality and meaning of life. These two questions pose significant problems 
for contemporary society, and faith and religion provide many needed and vital answers to some of their aspects. The answers must not be accepted only on a cognitive and rational level and translated into behaviour and life, especially for trauma victims, given in a compassionate, genuine, loving, and safe relationship where intense emotions and anxieties can be regulated. Scientific work in the sense of interdisciplinary dialogue, Pope Francis also strongly calls, can be of great help.

Keywords: trauma, post-traumatic growth, existential questions, unintentional blindness

\section{Nenamerna slepota in naša slika sveta}

Številne raziskave (Simons in Chabris 1999, 1059-1074; Hannon in Richards 2010, 309-319; Hughes-Hallett et al. 2015, 3184-3189; Remington, Cartwright-Finch in Lavie 2014, 1-11; Oktay in Cangöz 2018, 59-66) so potrdile fenomen tako imenovane nenamerne slepote. Raziskave (Chabris et al. 2011, 150-153) so pokazale, da nastopa tudi v dogodkih vsakdanjega življenja. Nenamerna slepota je nezmožnost videti dobro vidne objekte, ki jih direktno gledamo, ko je naša pozornost drugje (Mack 2003, 180). Navadno se izraz uporablja za vidne objekte, lahko pa tudi za druge (slušne, tipne ipd.) (Mack 2003, 180). S fenomenom nenamerne slepote je povezan fenomen selektivne pozornosti. Da bi bili v naših nalogah (prebrati časopis) učinkoviti, je treba, da procesiramo za naloge pomembne informacije (smo osredinjeni na besede v časopisu), hkrati pa ignoriramo za naloge nepomembne informacije (pogovore okrog nas v polni restravraciji) (Cosman in Vecera 2012, 576).

V znameniti raziskavi, ki sta jo izvedla, sta Simons in Chabris (1999) udeležencem prikazala posnetek, $v$ katerem si trije igralci bele in črne ekipe podajajo žogo. Glede na njune ugotovitve, ki so bile pozneje v drugih raziskavah tudi večkrat potrjene, približno polovica opazovalcev ne vidi osebe, oblečene v gorilo, ki se prikaže in sprehodi čez celotno sceno v posnetku, če se opazovalcem naroči, naj štejejo število podaj bele ekipe. Ta in podobne raziskave nam kažejo, da procesi v možganih torej močno izbirajo, kaj bodo opazili ali naredili pomembno celo $v$ fizičnem okolju, kaj šele v našem socialnem ali psihičnem. Naše slike realnosti so tako močno filtrirane.

Fenomen nenamerne slepote in selektivne pozornosti nam pomaga laže razumeti nekatera ekstremna, na primer negativna stališča nekaterih do zakonskega partnerja, do nošenja mask pri ukrepih zaradi virusa COVID-19, do katoliške Cerkve in tudi do vere. Ta stališča so odvisna od tega, katere njihove vidike bomo naredili za pomembne in za katere bomo nenamerno (seveda pa lahko tudi namerno) slepi. V depresiji se, na primer, močno zoži pozornost na negativno (Beck 2002, 31). Tudi v predajanju skušnjavi bi lahko v nekem smislu govorili o zožitvi pogledov, v katerih je deaktiviran reflektivni sistem (Vohs 2006, 217; Milyavskaya et al. 2015, 
677-678). Z razumevanjem teh fenomenov tudi laže razumemo težave novinarjev z objektivnostjo. Nekateri raziskovalci navajajo, da bi morali biti novinarji previdni celo pri navajanjih pričevanj in upoštevati možnost nenamernih napak (Blom 2018, 345-354).

Vsak od nas si sčasoma na podlagi svoje lastne pozornosti (pri tem igrajo pomembno vlogo tudi globoka čustva) ustvari neko sliko sveta, v katerem živi, oziroma si ustvarimo sistem, ki ga uporabljamo za interpretacijo sveta in življenja. Ta sistem ali slika vsebuje odgovore na za naše razmišljanje pomembna vprašanja, kakor so: Je življenje za nas varno in predvidljivo? So ljudje v njem dobri, neškodljivi, prijazni in zaupanja vredni? Je dobri Bog tisti, ki ne bo dovolil, da se nam v življenju kaj hudega zgodi? Ob tem pa je zelo pomembno vprašanje, koliko je ta naša, nedvomno do neke mere subjektivna slika sveta v skladu z realnostjo. Nekatere poenostavitve realnosti so nujno potrebne, da se lahko v kompleksnih dražljajih sploh znajdemo, vendar so lahko vir mnogih težav, če slike sveta niso posodobljene, če so naivne, preveč poenostavljene in nesofisticirane. Če bi vozili avto in pri tem nenehno gledali v aplikacijo z neposodobljenim Googlovim zemljevidom, namesto da bi gledali na cesto, bi verjetno imeli hude težave. Lahko se celo zgodi, da imamo celotna pomembna področja realnosti našega življenja brisana ali neizdelana.

\section{Travmatične izkušnje}

Naša podoba sveta, življenja in eksistencialnih vprašanj je lahko močno odvisna od travmatičnih izkušenj. Te izkušnje imajo namreč posebno vlogo v možganih in posebno spominsko naravo. Navadno spomini zbledijo v času, človek se že po nekaj dnevih težko spomni senzornih elementov (na primer barve, zvokov) neke določene izkušnje. $V$ travmatičnih spominih pa se slike, barve, čustva, zvoki in telesne reakcije prav vtisnejo ali vžgejo v možganske sisteme in lahko vztrajajo v precej nespremenjeni obliki mesece, leta in celo desetletja (Cvetek 2010, 55; van der Kolk, Hopper in Osterman 2001, 27; van der Kolk 1994, 254). So zamrznjeni v času (Shapiro 2001, 42; 47). Neka klientka, ki je bila spolno napadena in medtem zvezana, je ob razgovoru o dogodku po več letih čutila na zapestjih vrvi, torej imela celo fizične občutke, ki so bili ,zamrznjeni' v času. Kaj šele čustva in druge senzorne (npr. vidne, slušne, tipne) vtise! Problem travm, tudi spolnih zlorab, je torej, da se nepredelana travma ne konča, ko se izkušnja konča. Lahko bi rekli, da je ujeta $v$ neke vrste časovni zanki in se lahko nenehno podoživlja ali retravmatizira, ko kaj spomni na njo. Tudi zato so takšne izkušnje tako problematične in v preteklosti so morda strokovnjaki premalo osveščali o tem.

Travmatične izkušnje so dokaj pogoste. Po ozki definiciji travme, kakor je opisana v klasifikaciji DSM (American Psychiatric Association 2013, 271), travme doživi 60-90 \% ljudi (Benjet et al. 2016, 334), po širši definiciji pa praktično vsi, in to večkrat. Rezultati raziskave, ki smo jo na naši fakulteti opravili na odrasli slovenski populaciji glede pogostosti takšnih dogodkov (Cvetek, Ahčin et al. 2006), so prikazana v tabeli 1. 


\begin{tabular}{|c|c|c|c|}
\hline & $\%$ enkrat & $\%$ večkrat & Skupaj \\
\hline 1. Življenjsko nevarna bolezen odgovarjajočega & 9,44 & 4,41 & 13,85 \\
\hline $\begin{array}{l}\text { 2. Življenjsko nevarna nesreča ali poškodba odgovarja- } \\
\text { jočega (npr. avtomobilska, letalska, pri delu...) }\end{array}$ & 21,3 & 5,83 & 27,13 \\
\hline $\begin{array}{l}\text { 3. Uporaba fizične sile ali orožja na odgovarjajočem v } \\
\text { ropu ali napadu }\end{array}$ & 3,89 & 1,06 & 4,95 \\
\hline $\begin{array}{l}\text { 4. Smrt bližnjega družinskega člana, intimnega partner- } \\
\text { ja ali zelo bližnjega prijatelja odgovarjajočega zaradi } \\
\text { nesreče, umora ali samomora }\end{array}$ & 19,49 & 8,94 & 28,43 \\
\hline $\begin{array}{l}\text { 5. Fizična prisila (starša, drugega družinskega člana, } \\
\text { intimnega partnerja, tujca ali koga drugega) v spolno } \\
\text { občevanje ali v oralni ali analni spolni odnos proti volji } \\
\text { odgovarjajočega ali ko je bil odgovarjajoči nemočen, ko } \\
\text { je spal ali bil omamljen }\end{array}$ & 2,53 & 1,95 & 4,49 \\
\hline $\begin{array}{l}\text { 6. Poleg izkušenj iz prejšnjega vprašanja izkušnje doti- } \\
\text { kov privatnih (intimnih) delov telesa odgovarjajočega; } \\
\text { prisila odgovarjajočega, da se dotika telesa drugega, ali } \\
\text { poskus prisile, da bi imel nekdo spolne odnose proti } \\
\text { volji odgovarjajočega }\end{array}$ & 7,25 & 6,74 & 13,99 \\
\hline $\begin{array}{l}\text { 7. Večkratno oklofutanje, pretep ali drugačen napad ali } \\
\text { poškodba odgovarjajočega v otroštvu, ki jo zagrešijo } \\
\text { starši, skrbnik ali druga oseba }\end{array}$ & 5,86 & 31,47 & 37,33 \\
\hline $\begin{array}{l}\text { 8. Obrcanje, pretep, oklofutanje ali kaka drugačna } \\
\text { fizična poškodba odgovarjajočega v odraslosti, ki jo } \\
\text { zagreši intimni partner, oseba, s katero je bil odgovar- } \\
\text { jajoči na zmenku, družinski član, tujec ali kdo drug }\end{array}$ & 6,97 & 5,87 & 12,84 \\
\hline $\begin{array}{l}\text { 9. Večkratno zasmehovanje, poniževanje in ignoriranje } \\
\text { odgovarjajočega, ki jih zagrešijo starši, intimni partner } \\
\text { ali družinski član }\end{array}$ & 1,94 & 32,54 & 34,47 \\
\hline $\begin{array}{l}\text { 10. Poleg že opisanih izkušenj grožnja odgovarjajoče- } \\
\text { mu z orožjem, kakor je nož ali pištola }\end{array}$ & 5,86 & 2,5 & 8,36 \\
\hline $\begin{array}{l}\text { 11. Navzočnost odgovarjajočega pri umoru, resni } \\
\text { poškodbi, spolnem, fizičnem nasilju ali pri napadu }\end{array}$ & 6,69 & 6,7 & 13,39 \\
\hline $\begin{array}{l}\text { 12. Druge situacije z možnostjo resne poškodbe ali } \\
\text { nevarnosti za življenje odgovarjajočega - vključenost v } \\
\text { vojaški spopad ali življenje na vojnem območju }\end{array}$ & 6,68 & 1,91 & 8,59 \\
\hline $\begin{array}{l}\text { 13. Resen požar, potres, poplava, plaz ali druga narav- } \\
\text { na nesreča }\end{array}$ & 12,77 & 7,5 & 20,28 \\
\hline $\begin{array}{l}\text { 14. Življenjsko nevarna bolezen bližnjega prijatelja ali } \\
\text { družinskega člana odgovarjajočega }\end{array}$ & 34,88 & 20,9 & 55,78 \\
\hline $\begin{array}{l}\text { 15. Izkušnja, da je bil bližnji prijatelj ali družinski član } \\
\text { žrtev resnega napada, mučenja, ugrabitve ali vzet za } \\
\text { talca }\end{array}$ & 4,48 & 2,48 & 6,96 \\
\hline $\begin{array}{l}\text { 16. Razbijanje stvari, ki ga zagrešijo starši odgovarjajo- } \\
\text { čega, ali njihovo medsebojno poškodovanje }\end{array}$ & 6,42 & 19,19 & 25,61 \\
\hline 17. Ločitev ali razhod staršev odgovarjajočega & 9,88 & 1,15 & 11,03 \\
\hline 18. Odvzem odgovarjajočega njegovi družini & 8,56 & 4,17 & 12,73 \\
\hline
\end{tabular}

Opomba: \% enkrat - procent odgovarjajočih udeležencev, ki so neko travmo oziroma hujši stresni dogodek doživeli enkrat; \% večkrat - procent odgovarjajočih udeležencev, ki so neko travmo oziroma hujši stresni dogodek doživeli večkrat; Skupaj - sešteti procenti za eno in za več doživetij neke travme oziroma hujšega stresnega dogodka.

Tabela 1: Procent nastopanja nekaterih vrst travme oziroma večjih stresnih dogodkov v slovenski populaciji. 


\section{Travmatične izkušnje in njihov vpliv na našo podobo sveta in življenja}

Jedro problema težav ali psihopatologije, ki se razvije po travmi, lahko pogosto vidimo kot problem regulacije čustev. Mnogi strokovnjaki (Shapiro 2001, 47; Peterson 2017a, 2019) pa kot jedro takšnih težav ali psihopatologije vidijo tudi v tem, da je slika, podoba realnosti (npr. ali smo v nevarnosti ali ne) izkrivljena. Že za samo potravmatsko stresno motnjo je značilno, da posameznik v sedanjosti, ko ni realnih razlogov za to, podoživlja pretekle spomine (Svetovna zdravstvena organizacija 2018). Če se petdeset let star odrasel posameznik, ki ga je mama kot otroka pretepala, s strahom, veliko frustracijo in anksioznostjo odzove na pogovor $\mathrm{s}$ svojo mamo, to ni ustrezna reakcija na sedanjo realnost. Mama mu ne pomeni več grožnje, da ga bo fizično pretepla, če je, denimo, ta mama petinsedemdesetletna invalidka na vozičku (Shapiro 2001,47 ). Če so nekega otroka nadlegovali vrstniki, to še vedno lahko nosi s sabo kot odrasel človek - v drži, v predvidevanjih o ljudeh, v reakcijah, strahu, negotovosti, pri štiridesetih letih je tej sliki realnosti rok uporabe že zdavnaj potekel, vendar ni posodobljena, da bi odsevala realnost sedanjosti (Peterson 2017a).

Raziskave kažejo, da je eden od večjih dejavnikov za psihopatologijo po travmi (korelacije tudi do 0,5) (Park, Mills in Edmondson 2012, 70; Peterson 2019), koliko travma (lahko pa tudi dogodki, kakor so ločitev, afera ali izdajstvo) zruši posameznikov sistem prepričanj o svetu ali razumevanja sveta. Koliko je torej dogodek tako nepričakovan, da ga posameznik ne more vključiti v okvir sistema, ki ga uporablja za svoje interpretacije sveta in življenja in narave človeka.

Travmo definitivno lahko razumemo kot veliko zlo, ki se lahko prenaša iz generacije v generacijo, nekatere novejše raziskave nakazujejo celo medgeneracijski prenos travme prek epigenetike (Perroud et al. 2014, 334-344; Jawaid, Roszkowski in Mansuy 2018, 7-20). Raziskave tudi potrjujejo možne številne negativne biološke, psihološke, socialne in duhovne posledice. Pa vendar, stroka ima tudi dobre novice za žrtve travm. Raziskave predvsem v zadnjem času posvečajo večjo pozornost tudi tako imenovani potravmatski rasti, pozitivnim izidom travme, ki so predmet te razprave in ki seveda ni preprosta in je vsi ne zmorejo. Vendar 10-77\% oseb, ki jih prizadene travma, doživi pozitivne psihološke spremembe po travmi (Wu et al. 2019, 408). Tako jih je v metaanalizi, v katero je bilo vključenih 10181 udeležencev, 52,58 \% poročalo o srednjih do velikih stopnjah potravmatske rasti (Wu et al. 2019, 412).

Čeprav torej travma lahko povzroči, da so nekatera področja življenja manj izdelana in v skladu z realnostjo, pa raziskave potravmatske rasti kažejo, kako travma lahko pomaga, da je naš sistem interpretacije in razumevanja sveta bolj realen, sofisticiran, z manj pomembnimi področji življenja, ki jih ne vidimo, pa tudi z manj varanja samega sebe (Gersons et al. 2020, 260; Vis in Boynton 2008, 70-80; Sigmund 2003, 227). Navajamo nekaj zgledov, ko lahko travmatična izkušnja povzroči bolj realen pogled na svet in življenje.

- »Svet lahko kontroliramo, in če lepo in pravilno (dobro) živimo svoje življenje, igramo po pravilih v življenju, zaupamo po svoji predstavi v dobrega Boga, se nam 
ali našim bližnjim slabe stvari ne bodo zgodile. « Travmatična izkušnja nam lahko pokaže, da se v življenju zgodijo težke stvari, ki lahko niso pod našo kontrolo.

- »Svet/življenje je varno. « Življenje ni absolutno varno, v bistvu je lahko zelo nevarno. Vsi namreč umremo, zato bi lahko rekli, da je smrtno nevarno. Ni pa seveda kompletno nevarno na vsakem koraku in v vsakem trenutku.

- „Verjetno mi bo uspelo, da bom v življenju srečen in brez večjih problemov, ustvaril bom srečno družino ali življenje. « Raziskave in klinična praksa kažejo, da je zelo majhen procent ljudi dalj časa brez hujših problemov vsaj na enem področju svojega življenja. V življenju bomo zelo verjetno imeli najmanj eno resno kronično bolezen, verjetno vsaj dve. Svetovna zdravstvena organizacija $(2001,20)$ poroča, da samo mentalne in vedenjske motnje prizadenejo več kakor $25 \%$ ljudi. Večja raziskava (Kessler et al. 2007, 172) pa je pokazala, da je pričakovani procent ljudi, ki imajo v svojem življenju mentalno motnjo (največkrat depresivno ali anksiozno) v Franciji 47,2 \%, v Nemčiji 33 \%, v Italiji 26 \%, na Nizozemskem 42,9\%, v Belgiji 37,1 \%, v Španiji 29 \% in v ZDA 55,3 \%. Če nimamo problemov na področju zdravja, so lahko problemi na področju odnosov, financ, otrok, staršev, poklica in podobno. Če večjih problemov nimamo sami, je velika verjetnost, da jih imajo naši bližnji. Zelo verjetno bomo v življenju nekajkrat na robu ali prek roba svojih zmogljivosti reševanja problemov. Novejše psihološke teorije (terapija sprejemanja in predanosti) poudarjajo, da plačamo precejšen davek za tako imenovani teror sreče oziroma za zahteve, da je v našem življenju vse funkcionalno, uspešno in brez problemov in trpljenja (Harris 2008, 8-10). Večje zavedanje o temnih aspektih življenja pa je pomembno, ker lahko pomeni tudi večje zavedanje o njegovih svetlih oziroma lepih plateh (Vachon, Bessette in Goyette 2016, 185).

- »Ljudje imajo dobre namene, verjamem v dobro ljudi, niso nevarni. « Ljudje imamo lahko zelo temne motivacije, in to tudi zavestne in premišljene. Če ne izdelamo bolj sofisticiranega in manj naivnega pogleda na svet in ljudi, lahko hitro postanemo žrtev manipulacije (Peterson 2017b). V račun je treba vzeti obstoj zlobnosti v ljudeh, s tem pa tudi obstoj zlobnosti v sebi (Peterson 2017c; 2017d). Pastoralna konstitucija o Cerkvi v sedanjem svetu v zvezi s tem navaja: „Kajti če človek gleda v svoje srce, odkriva, da je nagnjen tudi k zlu in pogreznjen v mnogotero zlo, ki ne more izvirati od njegovega dobrega Stvarnika. « (GS, tč. 13,1) Biti dober ob vseh tragikah, pa tudi krivicah, ki se nam neizogibno dogajajo v življenju, ni preprosto. Tudi zase je dobro vedeti: če te življenje postavi v težke okoliščine in pritisne na prave gumbe, skrčiš svoj pogled, zelo verjetno postaneš zagrenjen, maščevalen in opravičuješ svoja slaba/zlobna dejanja. S tem lahko razumemo vrtiljak tragičnih zgodb tako na osebni ravni kakor tudi na ravni družbenih skupin in narodov. Če to res dojamemo, potem lahko pristno občudujemo Jezusa na križu in lahko do neke mere razumemo, kaj je bil tudi kot človeško bitje (celo Bog ga je zapustil) sposoben narediti s preoblikovanjem najhujših krivic v odpuščanje. Treba se je torej zavedati svoje kapacitete za zlo (Peterson 2017c; 2017d). Seveda pa razumevanje svojih temnih plati in temnih plati v vsakem posamezniku nikakor ne pomeni, da kakorkoli dajemo odgovornost žrtvam travme (ali jih celo krivimo), saj nikakor ne upravičujejo zlobnih dejanj. Žrtev travme mora dobiti sporočilo, da je 
storilec skopal luknjo, ne ona, lahko pa kaj naredi, da se v prihodnje izogne luknji (Peterson 2019). Imeti zemljevid, kako se v prihodnje izogniti takšnim ,luknjam', je lahko bistveno za okrevanje od potravmatskih simptomov.

\section{Travmatične izkušnje in eksistencialna vprašanja}

Poseben izziv pa pri travmi pomenijo eksistencialna vprašanja (Hoffman, Hoffman in Vallejos 2013, 3-6; Vis in Boynton 2008, 74). Travma namreč po večini definicij (klasifikacija DSM) (American Psychiatric Association 2013, 271) pomeni dogodek z grožnjo smrti ali resno poškodbo ( $v$ zadnjem času je še večji poudarek na spolnem nasilju) in tako pomembno zadeva predvsem dva od štirih glavnih virov anksioznosti in groze človekovega življenja glede na glavne avtorje (Yalom 1998, 172-173) eksistencialne psihoterapije.

\subsection{Neizogibna smrt za vsakega od nas in za ljudi, ki jih imamo radi}

V splošnem je še posebno sodobna družba razvila nekatere mehanizme, ki nam omogočajo, da se navadno ne ukvarjamo prav veliko s tem vprašanjem, in ki nam dajejo resda lažen občutek varnosti in neranljivosti. Pogosto se s to frustracijo naši vrojeni težnji po obstajanju in brutalni omejitvi našega bivanja na tem svetu soočamo tako, da z občutkom nelagodja gledamo proč (od smrti). Veliko psihične energije se porabi za zanikanje (na to mi še ni treba misliti; smrt je za starejše od mene; če bom zdravo živel, bom to preprečil) in za potlačevanje. Z evtanazijo se hočemo prepričati, da smrt ni nič groznega, lahko jo naredimo nebolečo in celo prijetno.

Precej jasno so s to anksioznostjo povezane psihične motnje, kakor so hipohondrija, panične motnje, kompulzivno umivanje rok, fobije in podobno. Predvsem eksistencialni terapevti (Yalom 2008, 18-30) pa ugotavljajo, da bi lahko to anksioznost, če bi le želeli, videli v ozadju še veliko več problemov in načinov našega vedénja (kopičenje premoženja, pretirana kontrola, razni družinski problemi, hlepenje po časti, odkloni v spolnosti...).

V splošnem je način, kako premagaš svoj strah pred nečim, to, da se prostovoljno soočiš z njim, seveda z ustrezno velikimi koraki, ne pa z begom od tega. Študentje lahko pomislijo na odlašanje ali soočanje $s$ kakim težkim izpitom. Ideja o škodljivosti potlačevanja in zanikanja se nedvomno v nekem določenem vidiku pripisuje Sigmundu Freudu, vendar je iskanje resnice, ne glede na stroške, močna krščanska ideja.

Problem zanikanja je tudi v tem, da je ob vedno številčnejših dogodkih, kakor so življenjske prelomnice, upokojitev, smrti bližnjih in podobno, vedno manj učinkovita.

Za nas pa je bistveno, kar Yalom (1980, 32-33), najbolj znani predstavnik današnje eksistencialne psihoterapije, tako lepo formulira: „Zanikanje smrti na katerikoli ravni je zanikanje posameznikove narave in povzroči vedno večje predirljive restrikcije (omejitve) zavedanja in izkušnje. Integracija ideje smrti nas reši; namesto da bi nas obsodila na eksistenco terorja ali potrtega pesimizma, deluje kot 
katalizator, ki nas pahne $v$ bolj pristne načine življenja in ojača naša zadovoljstva v življenju.«

Raziskovalci navajajo: če resnično hočemo pogledati na končnost našega življenja, gremo psihološko v drugo stanje zavedanja, imenovano stanje zavesti ali čuječnosti bivanja (30), drugače od stanja zavesti vsakodnevnih skrbi. Mnogi oboleli z razširjenim rakom - namesto da bi obstali otopeli in v obupu po diagnozi - doživijo prebujenje, začnejo voditi življenje bolj bogato. $V$ življenju postavijo prioritete in naredijo za nepomembne tiste stvari, ki so nepomembne. Rečejo na primer, da je škoda, ker so morali čakati toliko časa, da se naučijo živeti $(2008,34)$. Glede na to, da pa imamo vsi diagnozo smrtnosti že od rojstva, nam verjetno ni treba čakati na diagnozo raka, da bi dosegli te spremembe, če bi le hoteli bolj jasno pogledati na končnost našega življenja.

Ni pa gledanje smrti v svoji prihodnosti in inkorporiranje tega v naše sisteme nekaj preprostega. Eksistencialni psihoterapevti uporabljajo metaforo o strmenju ali zrenju v sonce (2008). Na prav poseben, pogosto celo preveč brutalen način, ko je dejstvo naše minljivosti prezentirano v zelo jasni luči, pa je to prav v travmatičnih izkušnjah, v katerih je navzoča grožnja smrti (Vachon, Bessette in Goyette 2016, 184). Ob tem so težko učinkovite kakršnekoli obrambne strategije pred zavedanjem. In po travmi se mora za neko mentalno in duhovno zdravje pogosto oseba vsaj do neke mere naučiti spoprijemati - namesto ga zanikati - z vprašanjem smrti.

Zanimivi so tudi mešani rezultati raziskav, ki ugotavljajo, kako sta strah ali anksioznost pred smrtjo povezana z verovanjem v posmrtno življenje in z religioznostjo. Raziskave namreč ne kažejo jasno, da bi vera pri vseh zmanjševala takšen strah ali anksioznost. Raziskava Mesarič $(2018,51)$, izvedena na Univerzi v Ljubljani, na Teološki fakulteti, je med anksioznostjo pred smrtjo in močjo religiozne vere odkrila korelacijo 0,036, to pomeni: praktično nično povezanost. Podobno govorijo tudi nekatere druge raziskave; res je, da so razlike med posameznimi verstvi in pa predvsem v tem, kakšna je ta vera (Bakan, Arli in Yıldız 2019, 2241; Jong et al. 2017, 11-12). Če nekdo verjame, da ga v posmrtnem življenju čaka kazen ali pekel, to verjetno ne vpliva razbremenjujoče na strah. Podrobnejša analiza teh ugotovitev in njihova implikacija sta zunaj namena te razprave, ob tem naj omenimo le papeža Frančiška (Frančišek 2013), ki v okviru teologije občutljivosti oziroma nežnosti (angl. tenderness) opozarja na razumevanje odnosa z Bogom kot na protistrup za strah. Verjetno bi bilo treba delati na večji implementaciji teh sporočil.

\subsection{Problem smisla v življenju}

Drugo tako pomembno eksistencialno vprašanje je, ali ima ob vseh težavah, trpljenju, omejenosti in končnosti našega življenja naše življenje kak pozitiven smisel.

$\checkmark$ splošnem številne raziskave kažejo na velik pomen smisla za človekovo zdravo funkcioniranje. Steptoe s sodelavci (Steptoe, Deaton in Stone 2015, 640-648) je odkril, da je med starejšimi udeleženci v 8,5-letnem obdobju umrlo 29,3 \% ljudi, ki so imeli majhen občutek smisla v življenju, v primerjavi z le 9,3 \% tistih, ki so 
imeli večji občutek smisla v življenju. Nekateri raziskovalci psihoterapije celo trdijo, da je pomoč klientom pri najdenju ustreznih smislov celo najpomembnejši cilj psihoterapije (Metz 2016, 27-33).

Glede na to, da so nekateri zaradi pozitivnega občutka smisla dali celo svoje življenje, lahko sklepamo, da je vsaj pri nekaterih občutek smisla še močnejši od strahu pred smrtjo.

Za našo razpravo pa so pomembne tri težave v zvezi s smislom, ki se izkazujejo $\checkmark$ raziskavah in literaturi.

1. V današnjem vsakdanjem modernem življenje je smisel lahko zelo zožen, včasih celo zreduciran na pridobivanje denarja in materialnega dobrega ali na prizadevanje za neke površinske in kratkotrajne užitke. Ti smisli so precej ranljivi, travmatična izkušnja, tudi s svojim sporočilom o minljivosti življenja in o postavljanju človeka v stanje zavesti ali čuječnosti bivanja, je hud udarec za takšne zožene, reducirane smisle, ki jih zamaje, seveda pa zagotavlja v tem smislu tudi priložnost za rast (Vachon, Bessette in Goyette 2016, 179; Sigmund 2003, 224).

2. Glede na zavedanje človeka o končnosti njegovega življenja se lahko pri ljudeh pokaže vir smisla, ki presega sámo življenje posameznika. Torej nekaj, kar ostane tudi po njem: na primer narediti neko pozitivno spremembo v svetu, narediti svet boljši, vzgojiti otroke, ki bodo nadaljevali tvoje vrednote; pomagati drugim in podobno. Vendar pa ne želimo predstavljati preveč preprostih rešitev na vprašanje smisla. Če razumsko razmišljamo, vsaj kakor razumsko tukaj pojmujemo, nam namreč zavedanje, da nam fosili s pomembno verjetnostjo kažejo, da vsaka vrsta nekoč izumre (tudi dinozavri so izumrli) in da bo čez par milijonov let sonce eksplodiralo in uničilo zemljo, da ne govorimo o črni luknji, ki nas bo vse požrla, lahko poraja neko določeno stopnjo frustracije, če seveda v enačbo, da se nam sploh izide, ne vstavimo tudi onostranstva.

Številne raziskave v splošnem kažejo, da imata resnična, notranja (intrinzična) vernost in religioznost posameznika lahko zelo pomembno vlogo pri razreševanju teh bistvenih življenjskih vprašanj. Teologija v tem smislu lahko zagotovi pomembne in prepotrebne odgovore. $V$ zvezi s tem pa je treba opozoriti na še neko težavo v zvezi s smislom, pa tudi širše.

3. Raziskovalci potravmatske rasti (Vis in Boynton 2008, 74; Mattis 2002, 317318) poudarjajo problem samo kognitivne ravni razumevanja smisla in potrebo po globljem dojemanju in izpeljavi v življenje teh razumskih odgovorov glede smisla. Ta proces imenujejo tudi presežno ustvarjanje smisla (Vis in Boynton 2008, 74). Odgovori na smisel življenja so namreč lahko zelo neavtentični, nepristni, nereflektirani in naloženi od zunaj. Zgolj nekakšni deklaratorni, kognitivni, dogmatični, razumski ali intelektualni odgovori imajo lahko majhno vrednost in so pogosto precej neuporabni. Lahko razumsko za svoje življenje vemo, da je smisel življenja ljubezen, služenje bližnjim, širjenje božjega kraljestva, slavljenje Boga ali kaj podobnega, vendar tega $v$ resnici ne dojemamo niti ne živimo. Lahko funkcioniramo, ne da bi se spraševali o veljavnosti, pravi vrednosti in pomenu teh smislov za naše življenje, odločitve in vedénje. Lahko nekdo iskreno misli, da veruje v Boga 
ali da je treba v življenju delati dobro in da ima plemenit smisel življenja, vendar njegova dejanja (prvenstveno prizadevanje za materialne dobrine, da ne govorimo o zlorabah) kažejo, da glede tega vara samega sebe. Psihoterapevti govorimo o stiku s sabo, tudi s svojimi sencami in temnimi čutenji in o včasih grozi, spoznati o sebi, kdo v resnici si. Šele ponižno opazovanje sebe in predvsem svojega vedénja nam bo povedalo, kakšna je naša vera ali smisel življenja in koliko so naši zavestni odgovori na smisel življenja lažni ali avtentični in resnični.

Za zmanjševanje notranje razcepljenosti posameznika med ,razumskim, intelektualnim ' védenjem, med tem, kar posameznik misli, in tem, kar potem dejansko odigrava v življenju, je verjetno lahko v veliko pomoč tudi v akademskem prostoru dialog med različnimi disciplinami (teologija, filozofija, psihologija ...), ki je tako poudarjen v apostolski konstituciji Veritatis Gaudium (Petkovšek 2019, 25-26). Predvsem pa je potrebno večje vključevanje različnih izkustvenih, doživljajskih, čustvenih, vedenjskih, problemskih, relacijskih in celo telesnih aspektov (novejše teorije govorijo celo o instinktu smisla življenja) v razumevanje, znanje in tudi poučevanje glede teh vprašanj. Vodičar (2016, 375-382) govori v tem smislu o vzgojni poti etike pristne skrbi za drugega, o poti zgleda in dialoga, ki morata nujno voditi v praktično življenje. Sedaj že mednarodno razširjena relacijska družinska terapija, ki jo je razvil prof. Gostečnik s sodelavci na Teološki fakulteti Univerze v Ljubljani (Gostečnik 2017; Gostečnik et al. 2011; Gostečnik et al. 2017; Cvetek 2015; Cvetek, Kompan Erzar et al. 2006; Gostečnik 2011; Gostečnik, Repič in Cvetek 2008; Cvetek, 2012; Gostečnik et al. 2009), s svojim globinskim celostnim pristopom, ki poudarja tudi telesne, temeljne afektivne, čustvene, pristne odnosne, vedenjske in duhovne aspekte človekovega doživljanja, lahko pomeni pomembno dodano vrednost omenjenemu dialogu tudi v svetovnem merilu. Ocenjujemo, da nas papež Frančišek (Frančišek 2013, 2019) prav s poslanico univerzitetnim ustanovam s poudarjanjem kerigmatične teologije, teologije občutljivosti ali nežnosti, kakor jo imenuje, s poudarjanjem potrebnosti upoštevanja čustev v teologiji in povezovanja teologije z življenjem spodbuja točno v tem smislu.

\section{Sklep}

Človek, ki bo v svoji eksistencialni poštenosti priznal svojo ranljivost in se spoprijel s svojimi ,sencami', bo tudi, tako kakor Kristus, lahko pristno pristopal k trpečim, izrinjenim in ponižanim. Še posebno pri tistih, ki so preživeli travme, je pomembno, da se raziskovanja eksistencialnih vprašanj in danosti življenja lotimo v sočutnem, ljubečem in varnem odnosu, v katerem je možno regulirati intenzivne afekte in anksioznost, ki se ob teh vprašanjih kažejo.

$\checkmark$ današnji družbi je bistveno, da teologija oznanja evangeljsko sporočilo na tem področju, in to v smislu, da ni treba zanikati ,senčnih' področij življenja. Karkoli že je bolečega, težkega, ,senčnega', vedno je možnost vstajenja in upanja. Nobene človeške neumnosti ni, ki ne bi mogla biti odpuščena, nobenega človeškega žalovanja, ki ne bi bilo do neke mere potolaženo, nobene človeške temine in sence, v 
katero ne bi mogel prodreti žarek svetlobe. Še tako zlomljen ali travmiran človek lahko v iskanju odgovorov tudi na eksistencialna vprašanja usmeri svoj pogled proti Soncu.

\title{
Kratica
}

\author{
GS - Koncilski odloki 1980 [pastoralna konstitucija O Cerkvi v sedanjem sve- \\ tu / Gaudium et spes (1965)].
}

\section{Reference}

American Psychiatric Association. 2013. Diagnostic and Statistical Manual of Mental Disorders: DSM-5. Arlington, VA: American Psychiatric Association.

Bakan, Ayse Berivan, Senay Karadag Arli in Metin Yıldız. 2019. Relationship between Religious Orientation and Death Anxiety in Elderly Individuals. Journal of Religion \& Health 58, št. 6:2241-2250.

Beck, Aaron T. 2002. Cognitive Models of Depression. V: Robert Leahy in E. Thomas Dowd, ur. Clinical Advances in Cognitive Psychotherapy: Theory and Application, 29-61. New York, NY: Springer Publishing Co.

Benjet, C., E. Bromet, E. G. Karam, R. C. Kessler, K. A. McLaughlin, A. M. Ruscio, V. Shahly, D. J. Stein, M. Petukhova, E. Hill, J. Alonso, L. Atwoli, B. Bunting, R. Bruffaerts, J. M. Caldasde-Almeida, G. de Girolamo, S. Florescu, $\mathbf{O}$. Gureje, Y. Huang, J. P. Lepine, N. Kawakami, Viviane Kovess-Masfety, M. E. Medina-Mora, F. Navarro-Mateu, M. Piazza, J. Posada-Villa, K. M. Scott, A. Shalev, T. Slade, M. ten Have, Y. Torres, M. C. Viana, Z. Zarkov in K. C. Koenen. 2016. The Epidemiology of Traumatic Event Exposure Worldwide: Results from the World Mental Health Survey Consortium. Psychological Medicine 46, št. 2:327-343.

Blom, Robin. 2018. Eyes Wide Shut: Failures to Teach Student Journalists about Eyewitness Error. Journalism \& Mass Communication Educator 74, št. 3:345-357.

Chabris, Christopher F., Adam Weinberger, Matthew Fontaine in Daniel J. Simons. 2011. You Do not Talk about Fight Club if You Do not Notice Fight Club: Inattentional Blindness for a Simulated Real-World Assault. i-Perception 2, št. 2:150-153.

Cosman, Joshua D., in Shaun P. Vecera. 2012. Object-Based Attention Overrides Perceptual Load to Modulate Visual Distraction. Journal of Experimental Psychology: Human Perception and Performance 38, št. 3:576-579.

Cvetek, Mateja. 2012. Čustveno odpuščanje v medosebnih odnosih. Bogoslovni vestnik 72, št. 2:281-295.

- - - 2015. Vloga čustvenega procesiranja v relacijski zakonski in družinski terapiji. V: Barbara Simonič, ur. Relacijska družinska terapija $v$ teoriji in praksi, 35-48. Ljubljana: Teološka fakulteta; Frančiškanski družinski inštitut.

Cvetek, Robert. 2010. Bolečina preteklosti: Travma, medosebni odnosi, družina, terapija. Celje: Mohorjeva družba.

Cvetek, Robert, Brigita Ahčin, Klaudija Ferčak, Barbara Kutnar, Tanja Milovanovič in Patricia Verbič. 2006. Pogostost travme v slovenski populaciji. Neobjavljeno poročilo. Teološka fakulteta, Univerza v Ljubljani; Frančiškanski družinski inštitut, Ljubljana.

Cvetek, Robert, Katarina Kompan Erzar, Tomaž Erzar in Christian Gostečnik. 2006. Relational Family Therapy. V: Jill S. Scharff in David E. Scharff, ur. New Paradigms for Treating Relationships, 51-61. New York, NY: Jason Aronson.

Frančišek. 2013. Govor udeležencem konference „The Theology of Tenderness in Pope Francis." Vatikan, 13. 9. https://press.vatican.va/content/salastampa/en/bollettino/ pubblico/2018/09/13/180913a.html (pridobljeno 10. 2. 2021).

- - - 2019. Govor udeležencem konference „Teology after Veritatis Gaudium in the Context of the Mediterranean." Vatikan, 21. 6. http:// www.vatican.va/content/francesco/en/speeches/2019/june/documents/papa-francesco_20190621_teologia-napoli.html (pridobljeno 10. 2. 2021).

Gersons, Berthold P. R., Mirjam J. Nijdam, Geert E. Smid in Marie-Louise Meewisse. 2020. Brief Eclectic Psychotherapy for PTSD. V: Lynn F. Bufka, Caroline V. Wright in Raquel Halfond, ur. Casebook to the APA Clinical Practice Guideline 
for the Treatment of PTSD, 139-161. Washington: American Psychological Association.

Gostečnik, Christian. 2011. Inovativna relacijska družinska terapija. Ljubljana: Brat Frančišek; Teološka fakuleta; Frančiškanski družinski inštitut.

- - - 2017. Relational Family Therapy: The Systemic, Interpersonal, and Intrapsychic experience. New York, NY: Routledge; Taylor \& Francis Group.

Gostečnik, Christian, Tanja Repič Slavič, Mateja Cvetek in Robert Cvetek. 2009. The Salvational Process in Relationships: A View from Projective-Introjective Identification and Repetition Compulsion. Journal of Religion and Health 48, št. 4:496-506.

Gostečnik, Christian, Tanja Repič Slavič, Saša Poljak Lukek in Robert Cvetek. 2011. Travmatsko izkustvo in dojemanje religioznosti. Bogoslovni vestnik 71, št. 2:265-277.

Gostečnik, Christian, Tanja Repič Slavič, Saša Poljak Lukek, Tanja Pate in Robert Cvetek. 2017. Emotional Detachment of Partners and the Sanctity of the Relationship with the Analyst as the Most Powerful Curative Factor. Journal of Religion and Health 56, št. 4:1123-1136.

Gostečnik, Christian, Tanja Repič in Robert Cvetek. 2008. Redemptive Experience in Relational Family Therapy: A Christian Perspective. Journal of Religion and Health 47:386-397.

Hannon, Emily M., in Anne Richards. 2010. Is Inattentional Blindness related to Individual Differences in Visual Working Memory Capacity or Executive Control Functioning? Perception 39, št. 3:309-319.

Harris, Russ. 2008. The Happiness Trap: How to Stop Struggling and Start Living. Boston, MA: Trumpeter Books.

Hoffman, Louis, Heatherlyn Hoffman in Lisa Vallejos. 2013. Existential Issues in Trauma: Implications for Assessment and Treatment. Prispevek predstavljen na znanstvenem zborovanju 121st Annual Convention of the American Psychological Association, julij/avgust. Honolulu, HI. https://www.researchgate.net/ publication/260002312_Existential_Issues_in_ Trauma_Implications_for_Assessment_and_ Treatment (pridobljeno 10. 2. 2021).

Hughes-Hallett, Archie, Erik K. Mayer, Hani J. Marcus, Philip Pratt, Sam Mason, Ara W. Darzi in Justin A. Vale. 2015. Inattention Blindness in Surgery. Surgical Endoscopy 29, št. 11:3184-3189.

Jawaid, Ali, Martin Roszkowski in Isabelle M. Mansuy. 2018. Transgenerational Epigenetics of Traumatic Stress. Progress in Molecular Biology and Translational Science 158:273-298.
Jong, Jonathan, Robert Ross, Tristan Philip, SiHua Chang, Naomi Simons in Jamin Halberstadt. 2017. The Religious Correlates of Death Anxiety: A Systematic Review and Meta-Analysis. Religion, Brain \& Behavior 8:1-17.

Kessler, Ronald C., Matthias Angermeyer, James C. Anthony, Ron De Graaf, Koen Demyttenaere, Isabelle Gasquet, Giovanni De Girolamo, Semyon Gluzman, Oye Gureje, Josep Maria Haro, Norito Kawakami, Aimee Karam, Daphna Levinson, Maria Elena Medina Mora, Mark A. Oakley Browne, José Posada-Villa, Dan J. Stein, Cheuk Him Adley Tsang, Sergio Aguilar-Gaxiola, Jordi Alonso, Sing Lee, Steven Heeringa, Beth-Ellen Pennell, Patricia Berglund, Michael J. Gruber, Maria Petukhova, Somnath Chatterji in T. Bedirhan Üstün. 2007. Lifetime Prevalence and Age-of-Onset Distributions of Mental Disorders in the World Health Organization's World Mental Health Survey Initiative. World Psychiatry 6, št. 3:168176.

Koncilski odloki. 1980. Ljubljana: Družina.

Mack, Arien. 2003. Inattentional Blindness: Looking without Seeing. Current Directions in Psychological Science 12, št. 5:180-184.

Mattis, Jacqueline S. 2002. Religion and Spirituality in the Meaning-Making and Coping Experiences of African American Women: A Qualitative Analysis. Psychology of Women Quarterly 26, št. 4:309-321.

Mesarič, Blanka. 2018. Strah pred umiranjem in lastno smrtjo. Magistrsko delo. Teološka fakulteta, Univerza v Ljubljani.

Metz, Thaddeus. 2016. The Proper aim of Therapy: Subjective Well-Neing, Objective Goodness, or a Meaningful Life? V: Pninit Russo-Netzer, Stefan E. Schulenberg in Alexander Batthyany, ur. Clinical Perspectives on Meaning: Positive and Existential Psychotherapy, 17-35. Cham: Springer International Publishing AG.

Milyavskaya, Marina, Michael Inzlicht, Nora Hope in Richard Koestner. 2015. Saying ,No' to Temptation: Want-to Motivation improves Self-Regulation by Reducing Temptation Rather than by Increasing Self-Control. Journal of Personality and Social Psychology 109, št. 4:677-693.

Oktay, Bahadır, in Banu Cangöz. 2018. I thought I saw ,Zorro': An Inattentional Blindness Study. Nöropsikiyatri Arşivi 55, št. 1:59-66.

Park, Crystal L., Mary Alice Mills in Donald Edmondson. 2012. PTSD as Meaning Violation: Testing a Vognitive Worldview Perspective. Psychological Trauma: Theory, Research, Practice, and Policy 4, št. 1:66-73.

Perroud, Nader, Eugene Rutembesa, Ariane Paoloni-Giacobino, Jean Mutabaruka, Léon Mutesa, Ludwig Stenz, Alain Malafosse in 
Félicien Karege. 2014. The Tutsi Genocide and Transgenerational Transmission of Maternal Stress: Epigenetics and Biology of the HPA Axis. The World Journal of Biological Psychiatry 15, št. 4:334-345.

Peterson, Jordan B. 2017a. How to Deal With Past Trauma and Get Past It: Interview with Stefan Molyneux. YouTube video, 6:09. 3. 9. https:// www.youtube.com/watch?v=pEoql5o6Vx8 (pridobljeno 10. 2. 2021).

- - - 2017b. Psy.cho.paths, Malevolence \& Predation. YouTube video, 10:43. 30. 12 2017. https://www.youtube.com/watch?v=hb_ bguhXko4 (pridobljeno 10. 2. 2021).

- - . 2017c. Your Capacity For Evil. YouTube video, 5:32. 8. 5. https://www.youtube.com/ watch? $v=S 8 c A D 0 D E c J E$ (pridobljeno 10. februarja 2021)

- - - 2017d. How Much Evil is Contained Within You? YouTube video, 3:51. 10. 8. https://www. youtube.com/watch?v=|7ufIBRZRKk (pridobljeno 10. 2. 2021).

- - . 2019. Why Does Betrayal Hurt so Much? YouTube video, 9:30. 26. 12. https://www. youtube.com/watch?v=beYCWfB9x_U (pridobljeno 10. 2. 2021).

Petkovšek, Robert. 2019. Teologija pred izzivi sodobne antropološke krize: preambula apostolske konstitucije Veritatis gaudium. Bogoslovni vestnik 79, št. 1:17-31.

Remington, Anna, Ula Cartwright-Finch in Nilli Lavie. 2014. I can See Clearly Now: The Effects of Age and Perceptual Load on Inattentional Blindness. Frontiers in Human Neuroscience 8:1-11.

Shapiro, Francine. 2001. Eye movement Desensitization and Reprocessing: Basic Principles, Protocols and Procedures. 2. izd. New York, NY: Guilford Press.

Sigmund, Judith A. 2003. Spirituality and Trauma: The Role of Clergy in the Treatment of Posttraumatic Stress Disorder. Journal of Religion and Health 42, št. 3:221-229.

Simons, Daniel J., in Christopher F. Chabris. 1999. Gorillas in our Midst: Sustained Inattentional Blindness for Dynamic Events. Perception 28, št. 9:1059-1074.

Steptoe, Andrew, Angus Deaton in Arthur A. Stone. 2015. Subjective Wellbeing, Health, and Ageing. The Lancet 385, št. 9968:640-648.

Svetovna zdravstvena organizacija. 2001. The World Health Report 2001: Mental Health; New Understanding, New Hope. Ženeva: Svetovna zdravstvena organizacija.

- - - 2018. International Classification of Diseases for Mortality and Morbidity Statistics (11th Revision): Posttraumatic Stress Disorder. Žene- va: Svetovna zdravstvena organizacija. https:// icd.who.int/browse11/I-m/en\#/

http\%3a\%2f\%2fid.who. int\%2ficd\%2fentity\%2f2070699808 (pridobljeno 20. 2. 2021).

Vachon, Mélanie, Prudence C. Bessette in Christine Goyette. 2016. Growing from an Invisible Wound: A Humanistic-Existential Approach to PTSD. V: Ghassan El-Baalbaki, ur. A Multidimensional Approach to Post-Traumatic Stress Disorder: From Theory to Practice, 179-203. London: InTech.

van der Kolk, Bessel A. 1994. The Body Keeps the Score: Memory and the Evolving Psychobiology of Posttraumatic Stress. Harvard Review of Psychiatry 1, št. 5:253-265.

van der Kolk, Bessel A., James W. Hopper in Janet A. Osterman. 2001. Exploring the Nature of Traumatic Memory: Combining Clinical Knowledge and Laboratory Methods. Journal of Aggression, Maltreatment \& Trauma 4:9-32.

Vis, Jo-Ann, in Heather Marie Boynton. 2008. Spirituality and Transcendent Meaning Making: Possibilities for Enhancing Posttraumatic Growth. Journal of Religion \& Spirituality in Social Work: Social Thought 27, št. 1-2:69-86.

Vodičar, Janez. 2016. Pojem žrtve v vzgoji: iz skrbi k odgovornosti. Bogoslovni vestnik 76, št. 2:373-383.

Vohs, Kathleen D. 2006. Self-Regulatory Resources Power the Reflective System: Evidence from Five Domains. Journal of Consumer Psychology 16, št. 3:217-223.

Wu, Xiaoli, Atipatsa C. Kaminga, Wenjie Dai, Jing Deng, Zhipeng Wang, Xiongfeng Pan in Aizhong Liu. 2019. The Prevalence of Moderate-to-high Posttraumatic Growth: A Systematic Review and Meta-Analysis. Journal of Affective Disorders 243:408-415.

Yalom, Irvin D. 1980. Existential Psychotherapy. New York, NY: Basic Books.

- - 1998. The Yalom Reader: Selections from the Work of a Master Therapist and Storyteller. New York, NY: Basic Books.

-- -. 2008. Staring at the Sun: Overcoming the Terror of Death. San Francisco, CA: Jossey-Bass. 